TP Periodica Polytechnica Civil Engineering

60(2), pp. 19922032016

DOI: $10.3311 /$ PPci.8328

Creative Commons Attribution (1)

RESEARCH ARTICLE

\section{A New Approach for Measurement of Tensile Strength of Concrete}

\author{
Vahab Sarfarazi, Abdolhadi Ghazvinian, Wulf Schubert, Hamid Reza Nejati, Raouf
}

Hadei

Received 15-06-2015, revised 15-09-2015, accepted 29-09-2015

\begin{abstract}
Tensile strength is one of the important mechanical properties of concrete. Indirect methods have been used up till now for its measurement. These methods though widely accepted, do not furnish the true tensile strength of concrete. In this paper, a compression to tensile load transformer device is developed to determine direct tensile strength of concrete. The cubic concrete samples with dimension of $15 * 19 * 6 \mathrm{~cm}$ containing internal hole with dimension of $75 \mathrm{~mm}$ is prepared using the mixture of cement, fine sand and water. This model is subjected to direct tensile loading by special loading device. A series of finite element analysis were performed using FRANC2D to analyse the effect of hole diameter on the stress concentration around the hole and to render a suitable criteria for determination of real tensile strength of concrete. Concurrent with direct tensile test, Brazilian test is performed to compare the results of two methods. Results obtained by this test are quite encouraging and shows that the direct tensile strength is clearly lower than the Brazilian test. The difference between the Brazilian and direct tensile strengths is about $33 \%$.
\end{abstract}

\section{Keywords}

Compression to tensile load converter $\cdot$ tensile strength of concrete $\cdot$ FRANC2D

\section{Vahab Sarfarazi}

Department of Mining Engineering, Hamedan University of Technology, Hamedan, 65155-579 P.O.B, Iran

e-mail: Sarfarazi@hut.ac.ir

\section{Abdolhadi Ghazvinian}

Rock Mechanics Division, Tarbiat Modares University, Tehran, Iran

\section{Wulf Schubert}

Institute for Rock Mechanics and Tunnelling, Technische Universität, Rechbauerstraße 12, A-8010, Graz, Austria

e-mail: schubert@tugraz.at

\section{Hamid Reza Nejati}

Rock Mechanics Division, Tarbiat Modares University, Tehran, Iran

\section{Raouf Hadei}

Faculty of Engineering, Imam Khomeini International University, Qazvin, Iran

\section{Introduction}

The tensile strength of concrete is a crucial design parameter in structures such as concrete dams, airfield runways, concrete roads and pavements, and other slabs. Therefore, many experimental and theoretical studies have been carried out to determine the tensile strength of concrete [1-10]. It is known that the stress obtained by breaking a specimen which is subjected to uniaxial loading, shows the real tensile strength of concrete (Fig. 1), but the tensile strength of concrete is obtained by indirect methods as splitting and flexural tests.

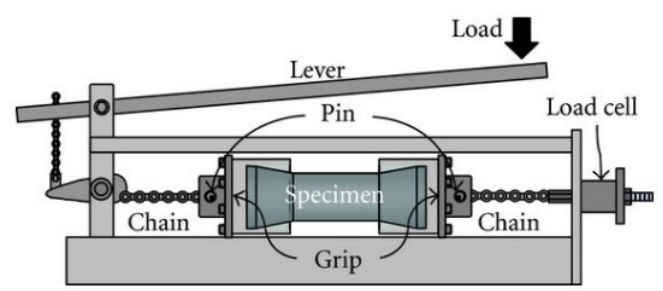

Fig. 1. Specimen under uniaxial tensile loading

A non-uniform state of stress is superimposed over the local stress fluctuations that are caused by the material structure itself. Because of this, these methods have disadvantages [11]. However, the tensile strength obtained from the uniaxial tensile test is more reliable than that of other test methods. But this test method requires much more care compared to indirect methods. Particularly, after the production of strong epoxy based adhesives, the uniaxial tensile tests are done with few troubles. Many experimental researches conducted in the past to determine the uniaxial tensile strength failed because of unexpected crushing which occurred as a result of local stress concentrations. Another difficulty in uniaxial tensile tests is that the test specimen is under the influence of moment effects during the tensile test due to eccentricity. Gomez [12] and Mier [13] reported that an increase in load eccentricity may decrease the tensile stress. Swaddiwudhipong et al. [14] studied the strain capacity in direct tension and the tensile strength of concrete produced with different types of cement at early ages in their tests.

Zain et al. [15] proposed some equations that indicate the splitting tensile strength of high strength concretes based on the 
compressive strength of concretes of any age.

The objective of this paper is to develop a new loading device called compression-to-tension transformer to apply a tensile stress to the concrete-like specimen. The proposed device will be designed and fabricated for use with most commercially available compression loading machines. It should be durable, inexpensive and easy to use. The concept is to apply compressive loads to the top and bottom of the hole and hence the specimen can subject to uniaxial tensile stress.

\section{Experimental test}

\subsection{Compression-to-tension load converter devices}

A compression-to-tension load transformer device (CTT) was developed to determine the tensile strengths of specimens with a hole in the middle. The primary design requirement is to allow alternating between the application of tensile load and compressive load on the same specimen while placing in a conventional compression machine. The Compression-to-tension load transformer device comprises several parts (Fig. 2). The part number 1 which has "U" shape has been built from stainless steel (Fig. 2a). This part is divided to two separate segments i.e. "L" and " 1 " shape segments. The part number 2 which have "I" shape is undividable (Fig. 2p). Dimension of these two parts is shown in Fig. 2 a and $b$.

The parts number 3 comprises two semi cylindrical stainless steels with dimension of $75 \mathrm{~mm} \times 10 \mathrm{~mm} \times 60 \mathrm{~mm}$ (Fig. 2r. $)$. The parts number 4 is composed of two similar blades with dimension of $20 \mathrm{~mm} \times 10 \mathrm{~mm} \times 190 \mathrm{~mm}$ (Fig. 2d).

The set up procedure of CTT device is consisted of six stages, as shown in Fig. 3 Firstly, the parts number 3 are inserted into hole (Fig. 3a). Secondly, the "L" shape segment of part number 1 is situated in left side of the specimen (Fig. $3 \mathrm{p}$ ). Thirdly, the first blade of part number 4 go through the hole so its upper surface is in contact to cylindrical steel, i.e. part of number 3 , and its lower surface is in contact to "L" shape segment (Fig. 36). Fourthly, the part number 2 is situated in right side of the specimen (Fig. 3c). Fifthly, the second blade of part number 4 go through the hole so its lower surface is in contact to cylindrical steel, i.e. part of number 3, and its upper surface is in contact with "I" shape segment, i.e. part of number 2 (Fig. 3d). Sixthly, the "l" shape segment is screwed to the "L" shape segment of part number 1 and the apparatus set up is completed. Therefore the upper cast is in contact with the lower cylindrical steel and the lower cast is in contact with upper cylindrical steel (Fig. 3 ). When this set up is situated between the uniaxial loading frames, the upper loading frame compress the upper cast so the lower part of the hole is compressed. In similar condition, the lower loading frame compresses the lower cast so the upper part of the hole is compressed. Compression of upper and lower parts of the hole brings the specimen to tensile loading (Fig. 3f).
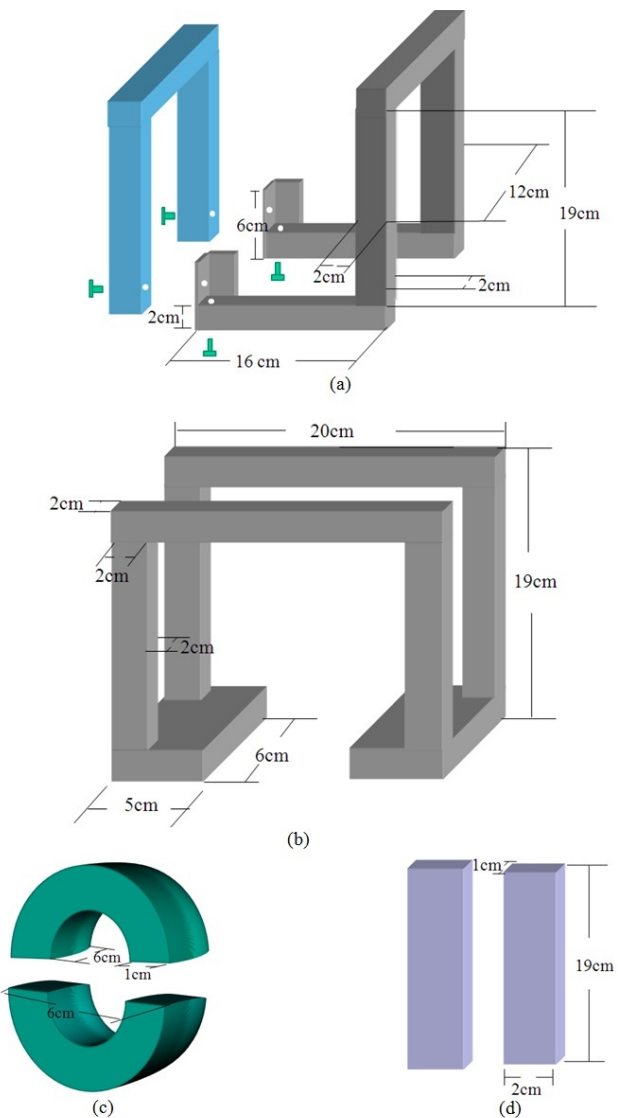

Fig. 2. The components of compression to tension converter load device.

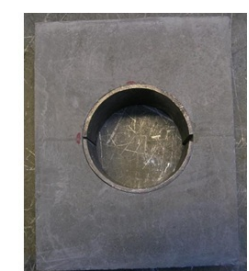

(a)

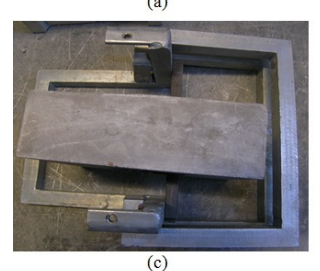

(c)

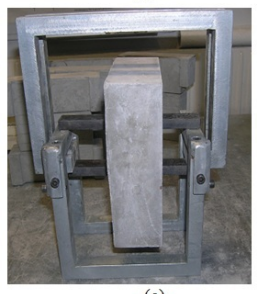

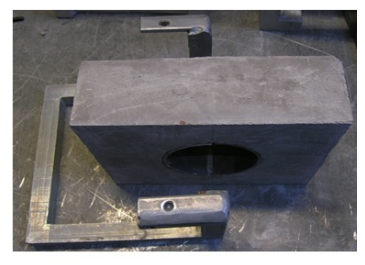
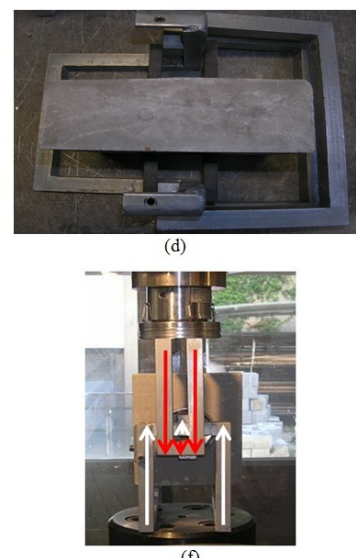

Fig. 3. The set up procedure of CTT device 


\subsection{The technique in preparation of the specimens}

The material mixture was prepared by mixing water, fine sand and Ordinary Portland Cement in a blender (Fig. 4h). crushed-limestone sand with $2.57 \mathrm{~g} / \mathrm{cm}^{3}$ of specific gravity and $2.75 \mathrm{~cm}^{2} / \mathrm{g}$ of fineness was used as fine aggregate.

The mixture was then poured into a fiberglass cast with internal dimension of $15 \times 19 \times 6 \mathrm{~cm}$ (Fig. $4 \mathrm{p}$ ). The cast consists of two discrete cubes, bolted together. The cast containing fresh mixture was vibrated (Fig. 4k) and then stored at room temperature for $8 \mathrm{~h}$ afterward, the specimens unmolded. Then a core with diameter of $7.5 \mathrm{~cm}$ and height of $60 \mathrm{~cm}$ remove from the centre of the samples using dry drilling (Fig. $4 \mathrm{~d}$ ) so the ratio of hole diameter $(7.5 \mathrm{~cm})$ to sample wide $(15 \mathrm{~cm})$ is 0.5 .

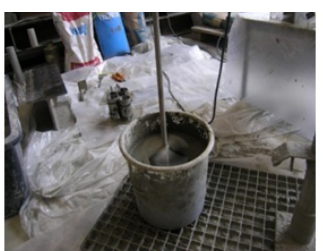

(a)

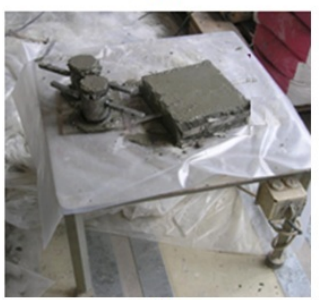

(c)

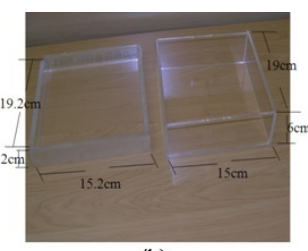

(b)

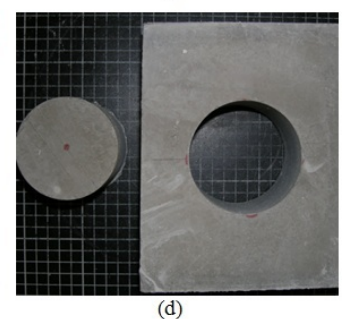

Fig. 4. The technique in preparing the internally hole specimens; a) mixing materials in a blender, b) a fiberglass cast, c) the fresh mixture is vibrated and d) drilling a core from the centre of the cubic sample.

\subsection{Tensile strength test procedure}

Fig. 5 shows test arrangement for direct tensile strength testing. The CTT device with a specimen is installed in a compression load frame (Fig. 5p. A 30-ton hydraulic load cell applies compressive load to the CTT end plates. An electronic load cell is used to measure the increase of the applied load. To isolate the effect of loading rate from the results a constant loading of $0.02 \mathrm{MPa} / \mathrm{s}$ was applied for all specimen. This rate is within the range recommended for the Splitting tensile strength testing by Denneman [16]. Three specimens are tested under direct tensile loading and three specimens are subjected under Splitting test. All specimens cracked along a horizontal line through the center of the hole when subjected to a vertical force. The failure is a splitting tensile failure because the failure happened intentionally along the horizontal axis with the help of two semi cylindrical steels (Fig. 6). Also Fig. 7 shows the tensile failure of specimen in Splitting test.

For calculation of far field tensile stress in direct tensile test, the far field failure load is divided to involve surface area of part number 4 which is $2 \mathrm{~cm} \times 6 \mathrm{~cm}$. But according to the Kirsch theory, whereas the far field tensile stress is distributed nonuniformly in sides of the hole therefore the far field tensile stress

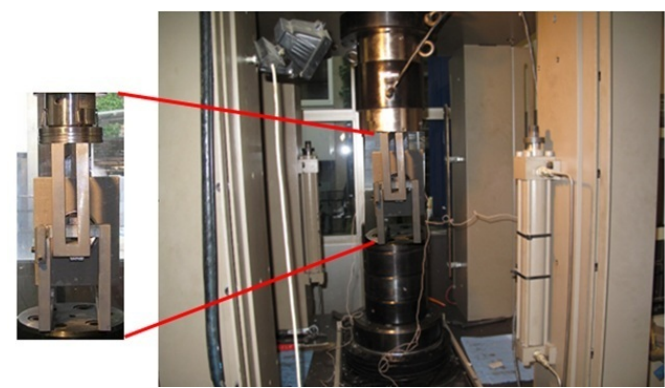

Fig. 5. Compression load frame.
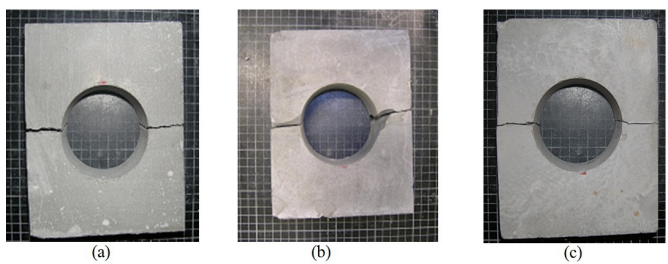

Fig. 6. The tensile failure pattern in samples.

could not be a proper agent for tensile strength of concrete material. The numerical simulation is necessary to determine a relationship between far field tensile stress, the ratio of hole diameter to sample wide and stress concentration at corners of the hole. The output of numerical simulation is a criterion which gives the real tensile strength of concrete block.

\section{Finite Element Simulation}

A two-dimensional finite element code named FRANC2D/L (FRacture ANalysis Code for 2-D Layered structures) was used to do the numerical modeling work. This code was originally developed at Cornell University and modified for multi-layers at Kansas State University, and is based on the theory of linear and nonlinear elastic fracture mechanics (Wawrzynek and Ingraffea, [17]). The general methodology starts with the preprocessing stage, where the geometry, mesh, material properties, and boundary conditions are specified. The modeling continues with post-processing stage where loading conditions, crack definition and crack growth process are specified. Fig. 8 shows finite mesh with boundary and loading conditions. The up and down sides of the model are fixed in $\mathrm{x}$ direction and left and right sides of the model are fixed in y direction. To obtain detailed distribution of the induced stresses up to 400 elements have been used in the models. Specimens with four different W/B rations; 0.15, $0.25,0.375$, and 0.5 ; were prepared. These models were subjected under internal tensile stress of $10 \mathrm{MPa}$. The analyses are

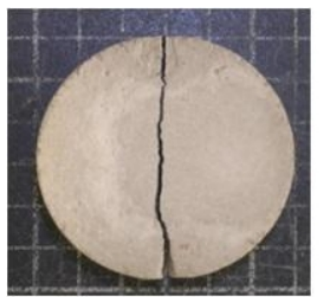

(a)

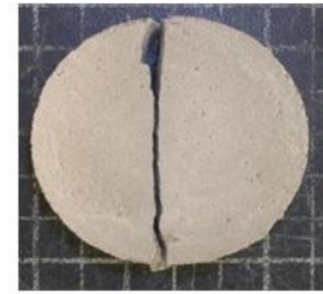

(b)
Fig. 7. Tensile failure of specimens in Splitting test. 
made on samples assuming that the concrete is linearly elastic and isotropic. The elastic modulus and Poisson's ratio of the specimens used in the model were assumed to be $25 \mathrm{GPa}$ and 0.20 , respectively.

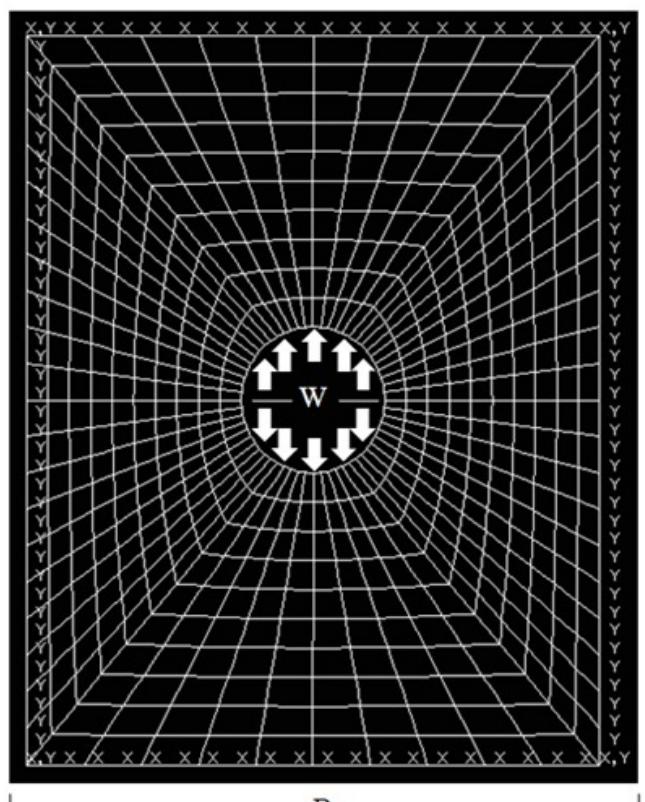

B

Fig. 8. Finite mesh with boundary and loading conditions

Objective of the model analyses is to determine that no compressive stress exists at the mid-length of the specimen. The specimen fails under tensile loading before failure by shear stress occurs at both ends of the specimen. The failure under tensile loading occurs at the mid-length of specimen. Fig. 9 shows tensile stress distribution in the samples for different ratios of hole diameter to sample wide. Fig.9 9 Shows concentrated tensile stress at the left and the right sides of hole
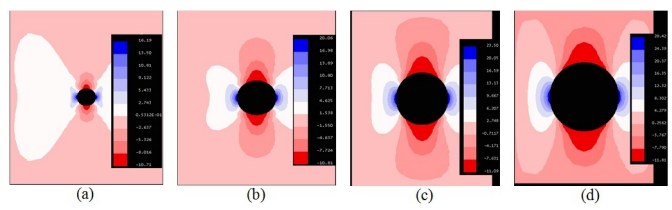

Fig. 9. Tensile stress distribution in the samples when $\mathrm{W} / \mathrm{B}$ is; a) 0.125 , b) 0.25 , c) 0.375 , d) 0.5 .

The compressive stress is also concentrated at top and bottom of the hole. Whereas the tensile strength of material is less than its compressive strength therefore these models have failure in left and the right sides of hole before failure under compression load at the vertical-section.

Fig. 10 shows distribution of the normalized tensile stress (S2) and shear stress (S) by far field tensile stress $(\mathrm{Pt})$ versus horizontal distance from centre of circle.

The maximum shear and tensile stress occurs near the applied load areas. Also the value of tensile stress at the corner of the circle is more than shear stress in all samples. Whereas the tensile strength of material is less than its shear strength therefore these models have tensile failure at the corner of specimen before failure under shear load at the centreline.

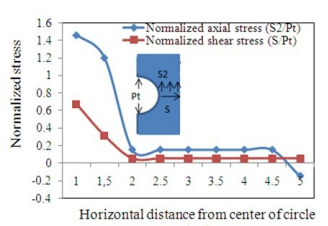

(a) ${ }^{(\mathrm{cm})}$

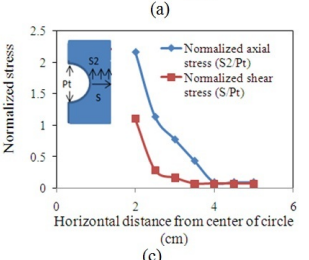

(c)

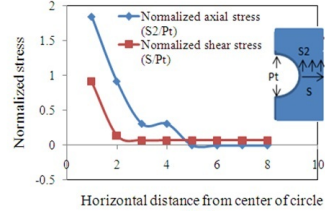

(b) ${ }^{(\mathrm{c})}$

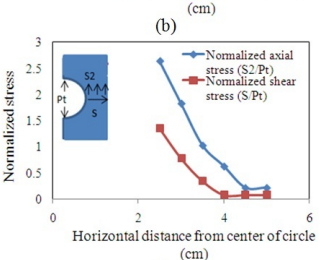

(d)
Fig. 10. The variation of normalized stress versus horizontal distance from circle center; the ratio of circle diameter to sample wide is a) 0.125 , b) 0.25 , c) 0.375 d) 0.5 .

From the results of numerical analysis it can be concluded that the model with internal bore is suitable for use with the compression-to-tension load transformer (CTT). Whereas distribution of tensile stress at the model is more than the far field tensile stress, therefore the far field tensile stress could not be used directly as tensile strength of concrete material. For determination of the real tensile strength of concrete, the relationship between concentrated tensile stress, far field tensile stress and hole diameter should be specified.

Fig. 11 shows the variation of normalized tensile stress concentration at the corners of the hole to the ratio of circle diameter to sample width.

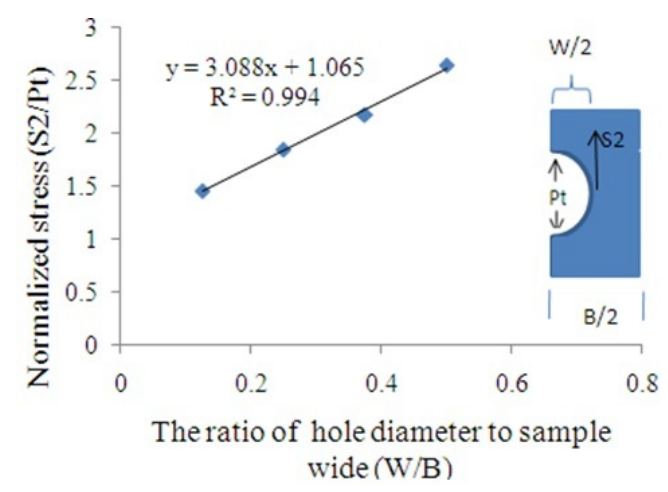

Fig. 11. The variation of normalized tensile stress consecration $(\mathrm{S} 2 / \mathrm{Pt})$ to the ratio of circle diameter to sample width (W/B).

The regression equation [i.e., Eq. (1)] can be used to predict $\mathrm{S} 2 / \mathrm{Pt}$ for any $\mathrm{W} / \mathrm{B}$ ratio between 0.125 and 0.5 :

$$
\frac{S 2}{P t}=3 \frac{W}{B}+1
$$

This equation shows that when far field tensile load $(\mathrm{Pt})$ is applied in the intact sample $(W=0.0)$, the tensile stress distribution in the model, s2, is equal to Pt. this means that the tensile load is distributed uniformly in the model in absence of the hole which is logically acceptable. This equation shows that when far field failure stress $(\mathrm{Pt})$ is applied to fine hole $(\mathrm{W} \sim 0$ ), the tensile stress concentration in the model, $\mathrm{S} 2$, is equal to $\mathrm{Pt}$. This means that, internal stresses in a fine hole act similar to the point loading with constant stress around the hole. The stress 
concentration around the hole increases by increasing the diameter (Fig. 11). This finding is in a good accordance with Kirsch solution results (Brady [18]).

From other point of view, this equation shows that when the model are loaded under far field tensile stress, the tensile stress concentration in the side of the hole can be calculated using Eq. (1). For example, when far field failure stress of $1.24 \mathrm{MPa}$ is applied in the CTT physical test with $W / B=0.5$, the tensile stress concentration at the hole corners (S2) is $3.1 \mathrm{MPa}$ according to Eq. (1). When $\mathrm{S} 2$ reach to $3.1 \mathrm{MPa}$, it can overcome to the tensile strength of material. Therefore the ultimate tensile stress side of the hole (S2) was registered as real tensile strength. Based on this finding, Table 1 shows the comparison between real tensile strength of CTT test and Splitting tensile strength.

Tab. 1. Results of direct tensile strength and Splitting strength test.

\begin{tabular}{ccc}
\hline $\begin{array}{c}\text { Sample No. } \\
(\mathrm{W} / \mathrm{B}=0,5)\end{array}$ & $\begin{array}{c}\text { Direct tensile } \\
\text { strength }(\mathrm{MPa})\end{array}$ & $\begin{array}{c}\text { Splitting tensile } \\
\text { strength }(\mathrm{MPa})\end{array}$ \\
\hline 1 & 3,1 & 4,5 \\
2 & 3,1 & 4,7 \\
3 & 2,9 & 4,4 \\
Average & 3,03 & 4,53 \\
\hline
\end{tabular}

\section{Comparison of the strength results}

Table 1 compares the tensile strength results obtained from two methods. The Splitting tension test yields the highest strength values due to the high stress gradient along the incipient crack plane (Zain et al. [14]). It is interesting to note that the difference between the Splitting and direct tensile strengths is about $33 \%$. The difference of the tensile strength from the two methods may therefore be partly governed by tensile stress distribution on the failure surface.

\section{Conclusions}

The CTT device is designed to obtain a direct tensile strength under uniaxial tensile and to induce extension failure under a true uniaxial tensile stress. The hole diameter at the mid-section of specimen is $75 \mathrm{~mm}$, which may raise an issue of circle size on the measured strengths. The effect of hole size on tensile strength of a concrete block was determined using numerical simulation. It has been concluded that as the circle size increases, the tensile stress concentration in the side of the hole along the horizontal axis increases in constant far field stress. The real concrete tensile strength is calculated based on Eq. (1). It is recognized here that the direct tensile strength is lower than the Splitting tensile strength so the difference between the Splitting and direct tensile strengths is about $33 \%$.

\section{Acknowledgement}

The author would like to thank Hamedan University of Technology (HUT) for funding this project under Contract No. $16 / 92 / 3 / \mathrm{P} / 111$.

\section{References}

1 Maso JC, La nature mineralogique des agregats facteur essentiel de la resistance des betons a la rupture et a l'action du gel, $\mathrm{PhD}$ thesis, University of Paul Sabatier; Toulouse, France, 1967. (in French).

2 Tiang Y, Shi S, Jia K, Hu S, Mechanical and dynamic properties of high strength concrete modified with lightweight aggregates presaturated polymer emulsion, Construction and Building Materials, 93, (2015), 1151-1156, DOI 10.1016/j.conbuildmat.2015.05.015

3 Luong M, Tensile and shear strengths of concrete and rock, Engineering Fracture Mechanics, 35(1-3), (1990), 127-135, DOI 10.1016/00137944(90)90190-R

4 Wan Ibrahim MH, Hamzah AF, Jamaluddin N, Ramadhansyah P, Fadzil AM, Split Tensile Strength on Self-compacting Concrete Containing Coal Bottom Ash, Procedia - Social and Behavioral Sciences, 198, (2015), 2280-2289, DOI 10.1016/sbspro.2015.06.317

5 Silva RV, de Brito J, Dhir RK, Tensile strength behaviour of recycled aggregate concrete, Construction and Building Materials, 83, (2015), 108-118, DOI $10.1016 /$ j.conbuildmat.2015.03.034

6 Gerges N, Issa C, Fawaz S, Effect of construction joints on the splitting tensile strength of concrete, Case Studies in Construction Materials, $\mathbf{3}$, (2015), 83-91, DOI 10.1016/j.cscm.2015.07.001

7 Liu X, Nie Z, Wu S, Wang C, Self-monitoring application of conductive asphalt concrete under indirect tensile deformation, Case Studies in Construction Materials, 3, (2015), 70-77, DOI 10.1016/j.cscm.2015.07.002

8 Mobasher A, Bakhshi M, Barsby C, Backcalculation of residual tensile strength of regular and high performance fiber reinforced concrete from flexural tests, Construction and Building Materials, 70, (2014), 234-253, DOI 10.1016/j.conbuildmat.2014.07.037

9 Larrard F, Malier Y, Engineering properties of very high performance concrete, E\&FN Spon; London, 1992.

10 Rocco C, Guinea GV, Planas J, Elices M, Review of the splitting-test standards from a fracture mechanics point of view, Cement and Concrete Research, 31(1), (2001), 73-82, DOI 10.1016/S0008-8846(00)00425-7

$11 \mathrm{Kim}$ J, Taha MR, Experimental and Numerical Evaluation of Direct Tension Test for Cylindrical Concrete Specimens, Advances in Civil Engineering, 2014, (2014), 1-8, DOI $10.1155 / 2014 / 156926$

12 Gomez JT, Shukla A, Sharma A, Static and dynamic behavior of concrete and granite in tension with damage, Theoretical and Applied Fracture Mechanics, 36(1), (2001), 37-49, DOI 10.1016/S0167-8442(01)00054-4

13 van Mier JGM, van Vliet MRA, Uniaxial tension test for the determination of fracture parameters of concrete: state of the art, Engineering Fracture Mechanics, 69(2), (2002), 235-247, DOI 10.1016/S0013-7944(01)00087-X

14 Swaddiwughipong S, Lu H, Wee T, Direct tension test and tensile strain capacity of concrete at early age, Cement and Concrete Research, 33(12), (2003), 2077-2084, DOI 10.1016/S0008-8846(03)00231-X

15 Zain MFM, Mahmud HB, Ilham A, Faizal M, Prediction of splitting tensile strength of high-performance concrete, Cement and Concrete Research, 32(8), (2002), 1251-1257, DOI 10.1016/S0008-8846(02)00768-8

16 Denneman E, Kearsley EP, Visser AT, Splitting tensile test for fibre reinforced concrete, Materials and Structures, 44(8), (2011), 1441-1449, DOI 10.1617/s11527-011-9709-x

17 Wawrzynek PA, Ingraffea AR, Interactive finite element analysis of fracture processes: An integrated approach, Theoretical and Applied Fracture Mechanics, 8(2), (1987), 137-150, DOI 10.1016/0167-8442(87)90007-3

18 Brady BHG, Brown ET, Rock Mechanics for Underground Mining (3rd Edition), Chapman \& Hall; London, 2006. 